\title{
GH-Producing Mammary Tumors in Two Dogs with Acromegaly
}

\author{
Atsuko MURAI ${ }^{1)}$, Naohito NISHII ${ }^{2)}$, Takehito MORITA ${ }^{3)}$ and Masashi YUKI ${ }^{1) *}$ \\ 1) Yuki Animal Hospital, 2-99 Kibacho, Minato-ku, Nagoya, Aichi 455-0021, Japan \\ ${ }^{2)}$ Laboratory of Veterinary Pharmacotherapeutics, Tottori University, Tottori 680-8553, Japan \\ ${ }^{3)}$ Laboratory of Veterinary Pathology, Tottori University, Tottori 680-8553, Japan
}

(Received 3 August 2011/Accepted 16 December 2011/Published online in J-STAGE 28 December 2011)

ABSTRACT. Two intact female dogs were admitted for growing mammary tumors. They had symptoms of acromegaly including weight gain, enlargement of the head, excessive skin folds, and inspiratory stridor. Serum concentrations of growth hormone (GH), insulinlike growth factor-I (IGF-I), and insulin were elevated in the two cases. From these findings, both dogs were diagnosed with acromegaly. In case 1, the GH, IGF-I, and insulin levels subsided after removal of the focal benign mammary tumors and ovariohysterectomy. In case 2, those levels subsided after removal of only focal mammary carcinoma. In both cases, immunohistochemical investigations for GH were positive in the mammary tumor cells but not in the normal mammary glands. We concluded that GH-producing mammary tumors caused the present acromegaly.

KEY WORDS: acromegaly, canine, mammary tumors.

doi: 10.1292/jvms.11-0361; J. Vet. Med. Sci. 74(6): 771-774, 2012

Acromegaly is caused by growth hormone $(\mathrm{GH})$ excess, characterized by overgrowth of the soft tissue, bone, and viscera. In humans and cats, acromegaly is commonly caused by pituitary adenomas producing $\mathrm{GH}[8,9]$. In dogs, on the other hand, acromegaly is usually caused by $\mathrm{GH}$ production at hyperplastic mammary glands $[12,13]$. Although $\mathrm{GH}$ is also produced by mammary tumors in dogs [14], there has been no report with clinically obvious acromegaly induced by GH-producing mammary tumors. In the present report, we described the clinical course of two dogs with acromegaly caused by GH-producing mammary tumors.

Case 1 was a 10 -year-old intact female Miniature Dachshund dog admitted for growing mammary tumors measuring 3-5 cm in diameter in the right fourth and fifth mammary glands, polyuria/polydipsia (PU/PD), and polyphagia for about 6 months. Clinical symptoms included weight gain (from 6.2 to $7.3 \mathrm{~kg}$ in 8 months), enlargement of the head, thickening of the skin, excess skin folds around the neck and limbs (Fig. 1), and inspiratory stridor. The dog had never received progestin treatment, and the last estrus was observed about 1 year before presentation.

Routine laboratory examination revealed lower packedcell volume (PCV, 28\%; reference range: 37-55\%) and leukocytosis $(24,900 / \mu l$; reference range: $6,000-17,000 / \mu l)$. Other values including complete blood cell count, glucose, total protein, ALT, AST, ALP, BUN, creatinine, and total cholesterol were within the reference ranges. Both serum concentrations of $\mathrm{GH}(30 \mathrm{ng} / \mathrm{ml}$; reference range: $0.5-3 \mathrm{ng} /$ $\mathrm{ml}$; determined by Porcine/Canine Growth Hormone ELI-

*Correspondence to: Yuki, M., Yuki Animal Hospital, 2-99 Kibacho, Minato-ku, Nagoya, Aichi 455-0021, Japan.

e-mail: yuki-masashi@mvf.biglobe.ne.jp

(C)2012 The Japanese Society of Veterinary Science
SA, Diagnostic Systems Laboratories, Inc., Webster, TX, U.S.A.) and insulin $[70.0 \mu \mathrm{U} / \mathrm{m} l$; reference range: $7.0-17.0$ $\mu \mathrm{U} / \mathrm{ml}$; determined by Mouse Insulin ELISA Kit (TMB) AKRIN-011T, Shibayagi, Gunma, Japan] were significantly elevated. Serum concentration of insulin-like growth factor-I (IGF-I) was markedly elevated $(388.0 \mathrm{ng} / \mathrm{ml})$ compared with 3 age- and body weight-matched normal healthy Miniature Dachshund dogs (72.1-165.0 ng/ml [5], IGF-I Somatomedin C II IRMA kit Siemens, Mitsubishi Chemical Medience Corporation, Tokyo, Japan) [4]. The serum concentration of progesterone was within the luteal phase level $(2.7 \mathrm{ng} / \mathrm{ml}$; reference range of luteal phase: 2.4-17.8 ng/ml; Canine Progesterone ELISA Test, Endocrine Technologies, Inc., Newark, CA, U.S.A.) (Table 1). No abnormality was observed by abdominal and thoracic radiologics or ultrasonography. Based on these results, the

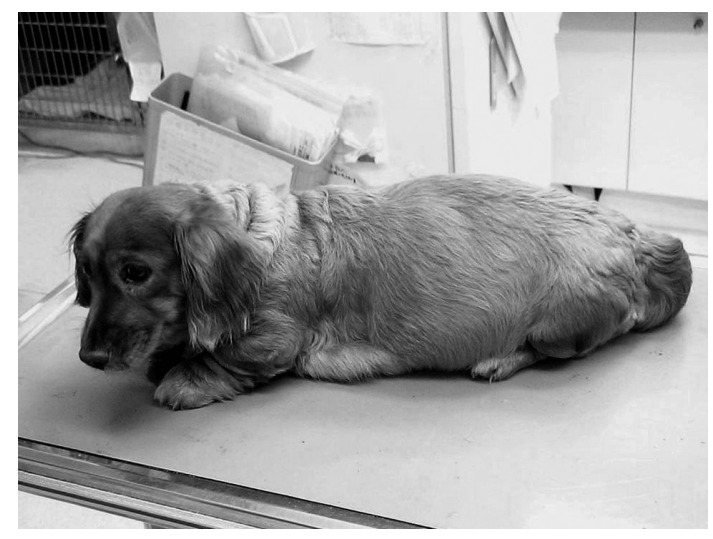

Fig. 1. Case 1, a 10-year-old intact female Miniature Dachshund dog, body weight of $7.3 \mathrm{~kg}$ before surgery. The dog had acromegalic signs including enlargement of the head and excess skin folds around the neck and limbs. 
Table 1. Serum GH, IGF-I, insulin and progesterone concentrations before and after surgery in cases 1 and 2

\begin{tabular}{lcccc}
\hline & $\begin{array}{c}\text { GH } \\
(\mathrm{ng} / \mathrm{m} l)\end{array}$ & $\begin{array}{c}\text { IGF-I } \\
(\mathrm{ng} / \mathrm{m} l)\end{array}$ & $\begin{array}{c}\text { insulin } \\
(\mu \mathrm{U} / \mathrm{m} l)\end{array}$ & $\begin{array}{c}\text { progesterone } \\
(\mathrm{ng} / \mathrm{m} l)\end{array}$ \\
\hline Case 1 & & & & \\
Before surgery & 30.0 & 388.0 & 70.0 & 2.7 \\
13th day after surgery & 0.7 & 60.2 & 13.0 & 1.9 \\
Case 2 & & & & \\
Before surgery & 5.0 & 1020.0 & 32.0 & 17.5 \\
23th day after surgery & 2.1 & 437.0 & 15.4 & 5.7 \\
Reference range & $0.5-3.0$ & $72.1-165^{\text {a) }}$ & $7.0-17.0$ & $2.4-17.8^{\text {b) }}$ \\
\hline
\end{tabular}

a) Values of 3 age- and body weight-matched normal healthy Miniature Dachshund dogs.

b) The reference range for progesterone was determined during the luteal phase of dogs.

dog was diagnosed with acromegaly.

The dog was treated by ovariohysterectomy and surgical excision of the focal mammary tumors 10 days after presentation. Histological examination revealed mammary complex adenomas and bilateral ovarian luteinization. Immunohistochemical investigation for GH (Rabbit anti-human GH antibody, Dako Cytomation, Glostrup, Denmark) revealed immunoreactivities in the mammary tumor epithelial cells, as shown in Fig. 2. These immunoreactivities were localized in the cytoplasm. There was no staining in the normal mammary glands surrounding the mammary tumors. PCV and serum concentrations of GH $(0.7 \mathrm{ng} / \mathrm{ml})$, IGF-I $(60.2 \mathrm{ng} / \mathrm{m} l)$, and insulin $(13.0 \mu \mathrm{U} / \mathrm{m} l)$ decreased to the normal range within 13 days after surgery (Table 1). Within 70 days after surgery, clinical signs including inspiratory stridor, excessive skin folds, and PU/PD disappeared, and body weight decreased (from 7.3 to $6.2 \mathrm{~kg}$ ), as shown in Fig. 3.

Case 2 was a 13-year-old intact female Papillon dog admitted for growing mammary tumors measuring $8 \mathrm{~cm}$ in diameter in the right fifth mammary gland and $2 \mathrm{~cm}$ in diameter in the right second mammary gland. The dog had abnormal weight gain (from 5.3 to $6.3 \mathrm{~kg}$ in 9 months), PU/ $\mathrm{PD}$, progressive inspiratory stridor, and excessive panting for about 6 months. Clinical examination revealed prominent skin folds around the neck, enlargement of the head (Fig. 4), large mammary tumors, and a periapical abscess. The patient had never received progestin treatment. The last estrus was observed 10 days before presentation.

Routine laboratory examination revealed no significant abnormalities. Serum concentrations of IGF-I (1,020.0 $\mathrm{ng} /$ $\mathrm{m} l)$ and insulin $(32.0 \mu \mathrm{U} / \mathrm{m} l)$ were significantly elevated, and the serum GH concentration $(5.0 \mathrm{ng} / \mathrm{m} l)$ was slightly higher than the normal range. Serum concentration of progesterone $(17.5 \mathrm{ng} / \mathrm{m} l)$ was within the luteal phase level (Table 1). From these results, the dog was diagnosed with acromegaly.

Although we planned mammary tumor excision and ovariohysterectomy, metastasis of the mammary tumor was suspected from thoracic radiographs before surgery. One of the mammary tumors was so large that the owner opted for the mammary tumor excision to improve the quality of life. Therefore, the mammary tumors were removed fo-

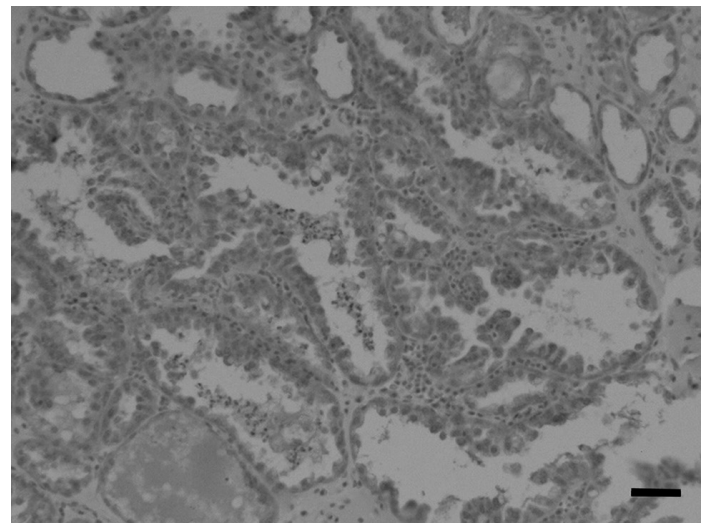

Fig. 2. Immunohistochemical investigation for $\mathrm{GH}$ in mammary complex adenoma in case 1 . The cytoplasm of neoplastic epithelial cells showed positive reactivities. Scale bar $=25 \mu \mathrm{m}$.

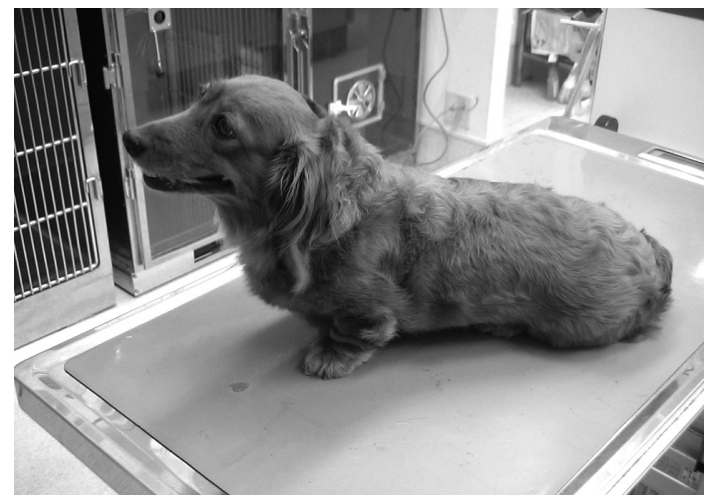

Fig. 3. Case 1 at 70 days after surgery. Body weight decreased to $6.2 \mathrm{~kg}$. The excess skin folds disappeared after surgery.

cally with regional lymph node. Histological examination of the large tumor revealed mammary complex carcinoma and metastasis to the regional lymph node. The other mammary tumor was diagnosed as complex adenoma. Upon immunohistochemical investigation for $\mathrm{GH}$, immunoreactivi- 


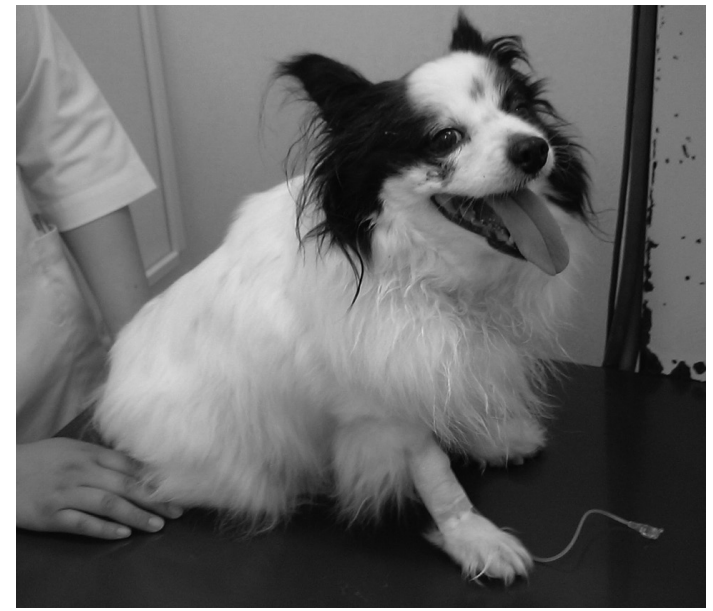

Fig. 4. Case 2, a-13-year-old intact female Papillon dog, body weight of $6.3 \mathrm{~kg}$ before surgery. The dog had excess skin folds around the neck, enlarged head, and periapical abscess.

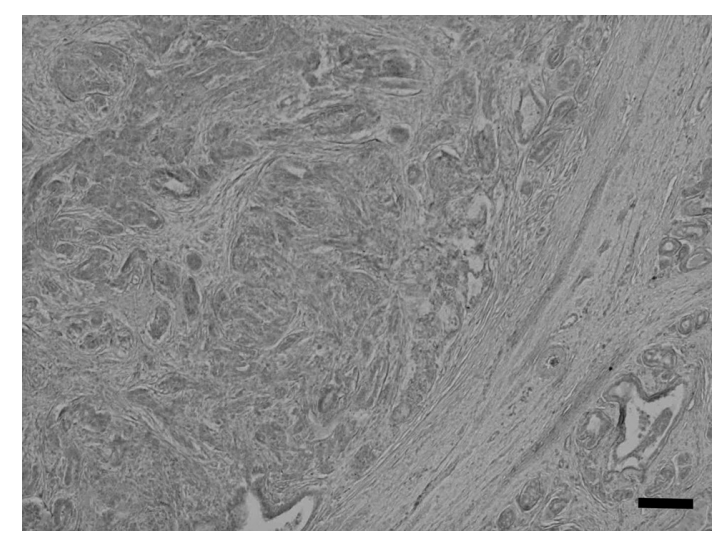

Fig. 5. Immunohistochemical analysis for GH in mammary complex carcinoma in case 2 . Cytoplasm of neoplastic epithelial cells showed positive reactivities for GH. Normal mammary glands, right bottom, were not stained. Scale bar $=50 \mu \mathrm{m}$.

ties were found in the cytoplasm of tumor epithelial cells. The normal mammary glands showed no immunoreactivities for GH (Fig. 5). Although serum concentrations of GH $(2.1 \mathrm{ng} / \mathrm{m} l)$, IGF-I $(437.0 \mathrm{ng} / \mathrm{m} l)$, and insulin $(15.4 \mu \mathrm{U} / \mathrm{m} l)$ dropped within 23 days after surgery (Table 1), clinical symptoms of inspiratory stridor and excessive skin folds did not improve.

Canine acromegaly typically occurs in middle-aged to elderly female dogs in the luteal phase or after administration of exogenous progestins $[2,6]$. Endogenous progesterone or exogenous progestins stimulate GH production in hyperplastic mammary glands in dogs $[6,12,13]$. This GH can act via the autocrine system to promote the growth of mammary glands or elevate systemic IGF-I secretion [10]. Excessive GH also induces glucose intolerance, which can lead to hyperinsulinemia and/or hyperglycemia. In case 1, anemia was observed before surgery and was improved to the normal range 13 days after surgery. Anemia has been reported in dogs with acromegaly or dogs treated with porcine GH. However, the exact mechanism causing anemia with these dogs remains unknown [10].

A previous report demonstrated that complete removal of normal mammary glands can reduce GH and IGF-I levels in dogs [13]. In the present cases, although the normal mammary tissue was left, removal of only the mammary tumors decreased the GH and IGF-I levels. In addition, the immunoreactivities for GH were found only in the mammary tumor cells but not in the normal mammary glands, suggesting that GH produced by mammary tumors caused the acromegaly. This is supported by a previous report that most mammary tumors produce GH in dogs [14]. However, in case 1, we could not exclude the possibility that endogenous progesterone produced by the ovary may serve to produce GH, because surgical removal of the mammary tumor was accompanied by ovariohysterectomy. In case 2 , the IGF-I level was not decreased to the normal range after surgery. Previous report demonstrated that IGF-I and GH concentrations were significantly higher in malignant mammary tumors in dogs, suggesting that IGF-I can be secreted by the mammary tumors, not only the liver, stimulated by GH [10]. Therefore, IGF-I secretion from another site, such as a metastatic mammary tumor, may cause the sustained high concentration of IGF-I in case 2 . In contrast to our cases, a previous study has shown that canine malignant mammary tumors contain high GH levels without acromegalic symptoms [10]. The differences that determine whether mammary tumors do or do not develop acromegaly remain unknown.

Canine acromegaly occurs spontaneously during the luteal phase. High physiologic levels of progesterone in the luteal phase increase GH levels, which can cause acromegaly [3]. In our cases, the serum progesterone concentrations were within the luteal phase levels. However, chronic excess of progesterone should not have existed in case 2, since the last estrus was observed only 10 days before presentation. That period was much shorter than the usual one that takes 3 to 5 weeks between the last estrus and onset of the acromegalic signs [3]. We therefore concluded that the GH production of mammary tumors may be independent of progesterone stimulation, at least in case 2. This hypothesis is supported by a previous report that mammary carcinomas express GH gene independently of progesterone [7, 14].

Ovariohysterectomy or withdrawal of progestin administration is the treatment of choice for canine acromegaly $[2,11,12]$. Recently, aglepristone, a progesterone receptor antagonist, was used to treat canine acromegaly [1]. We propose that surgical excision of mammary tumors may be an alternative treatment for canine acromegaly caused by GH-producing mammary tumors.

In conclusion, we diagnosed two dogs with spontaneous acromegaly. Surgical excision of mammary tumors decreased the serum concentrations of GH, IGF-I, and insulin. In addition, GH immunoreactivities were observed in the mammary tumors, but not in normal mammary glands. 
These results suggested that the acromegaly was induced by GH production in the mammary tumors. To the best of our knowledge, this is the first report providing concrete evidence of a causal relationship between GH-producing mammary tumors and naturally occurring canine acromegaly.

\section{REFERENCES}

1. Bhatti, S. F., Duchateau, L., Okkens, A. C., Van Ham, L. M., Mol, J. A. and Kooistra, H. S. 2006. Treatment of growth hormone excess in dogs with the progesterone receptor antagonist aglepristone. Theriogenology 66: 797-803. [Medline] [CrossRef]

2. Eigenmann, J. E. 1984. Acromegaly in the dog. Vet. Clin. North Am. Small Anim. Pract. 14: 827-836. [Medline]

3. Eigenmann, J. E., Eigenmann, R. Y., Rijnberk, A., van der Gaag, I., Zapf, J. and Froesch, E. R. 1983. Progesterone-controlled growth hormone overproduction and naturally occurring canine diabetes and acromegaly. Acta Endocrinol. (Copenh.) 104: 167-176. [Medline]

4. Eigenmann, J. E., Patterson, D. F., Zapf, J. and Froesch, E. R. 1984. Insulin-like growth factor I in the dog: a study in different dog breeds and in dogs with growth hormone elevation. Acta Endocrinol. (Copenh.) 105: 294-301. [Medline]

5. Jensen, A. L. and Hoier, R. 1995. Determination of insulin-like growth factor 1 in dogs using a commercially available immunoradiometric assay1). Eur. J. Clin. Chem. Clin. Biochem. 33: 939-945. [Medline]

6. Kooistra, H. S. 2005 Acromegaly and pituitary dwarfsm. pp. 1498-1502 In: Textbook of Veterinary Internal Medicine, 6th ed. (Etinger S. J. and Feldman E. C. eds.), Elsevier Saunders, Philadelphia.

7. Mol, J. A., van Garderen, E., Selman, P. J., Wolfswinkel, J., Rijinberk, A. and Rutteman, G. R. 1995. Growth hormone mRNA in mammary gland tumors of dogs and cats. J. Clin. Invest. 95: 2028-2034. [Medline] [CrossRef]

8. Nabarro, J. D. 1987. Acromegaly. Clin. Endocrinol. (Oxf.) 26: 481-512. [Medline] [CrossRef]

9. Niessen, S. J. 2010. Feline acromegaly: an essential differential diagnosis for the difficult diabetic. J. Feline Med. Surg. 12: 15-23. [Medline] [CrossRef]

10. Queiroga, F. L., Perez-Alenza, M. D., Silvan, G., Pena, L., Lopes, C. S. and Illera, J. C. 2008. Crosstalk between GH/IGFI axis and steroid hormones (progesterone, 17 beta-estradiol) in canine mammary tumours. J. Steroid Biochem. Mol. Biol. 110: 76-82. [Medline] [CrossRef]

11. Rijnberk, A., Eigenmann, J. E., Belshaw, B. E., Hampshire, J. and Altszuler, N. 1980. Acromegaly associated with transient overproduction of growth hormone in a dog. J. Am. Vet. Med. Assoc. 177: 534-537. [Medline]

12. Rijnberk, A. and Mol, J. A. 1997. Progestin-induced hypersecretion of growth hormone: an introductory review. J. Reprod. Fertil. Suppl. 51: 335-338. [Medline]

13. Selman, P. J., Mol, J. A., Rutteman, G. R., van Garderen, E. and Rijnberk, A. 1994. Progestin-induced growth hormone excess in the dog originates in the mammary gland. Endocrinology 134: 287-292. [Medline] [CrossRef]

14. van Garderen, E., de Wit, M., Voorhout, W. F., Rutteman, G. R., Mol, J. A., Nederbragt, H. and Misdorp, W. 1997. Expression of growth hormone in canine mammary tissue and mammary tumors. Evidence for a potential autocrine/paracrine stimulatory loop. Am. J. Pathol. 150: 1037-1047. [Medline] 